\title{
Justo Serna y Anaclet Pons, microHistoria. Las narraciones de Carlo Ginzburg. Granada: Comares, 2019, 184 pp.
}

Como casi todos los lectores de esta revista sabrán, en 1976, el por entonces casi desconocido historiador italiano, Carlo Ginzburg, publicaba una de sus obras más conocidas e influyentes: El queso y los gusanos. La traducción a otras lenguas no se hizo esperar y, poco a poco, este libro se dio a conocer en buena parte del mundo, incluyendo España, cuya versión en castellano solo se demoró cinco años, ya que, en 1981, la editorial de Mario Muchnik publicó la primera edición española. Desde entonces, tanto en el ámbito académico y universitario como fuera de él, la obra de Carlo Ginzburg ha conquistado a todo tipo de públicos, asociando su obra a la famosa etiqueta de "microhistoria". Y es que, justo con otros títulos míticos, El Queso y los gusanos, se ha dicho hasta la saciedad, es uno de los más interesantes ejemplos de "reducción de la escala" histórica, o, más concretamente, de la práctica de la microhistoria. Sin embargo, conocer en detalle el contenido de dicho libro así como estudiar la obra en conjunto del historiador italiano de origen judío, no es algo que haya ocupado a una nutrido número de historiadores españoles. Al contrario, el análisis minucioso de la obra de Ginzburg disfruta en España casi de un monopolio la mar de curioso. De hecho, además de la obra de Blanca Fernández García y de varias referencias en los manuales universitarios sobre historiografía, parece que solo los profesores Justo Serna y Anaclet Pons han dedicado esfuerzos encomiables a estudiar y a glosar, en profundidad, las bondades de la perspectiva historiográfica ginzburgiana. Ginzburg es una figura admirada. Y los dos primeros en admirar al historiador de Turín, son los propios autores del libro que comentamos.

Justo Serna y Anaclet Pons son dos historiadores culturales que ofrecen su docencia y magisterio en la Universidad de Valencia. Ambos son profesores de historia contemporánea y ambos llevan años interesados en el estudio de las distintas formas de "dar forma" al pasado, lo que les ha llevado a estudiar diversos autores y corrientes historiográficas actuales. Si bien muestran un encomiable interés intelectual por la obra de historiadores postmodernos como Hayden White, F.R. Ankersmit o Keith Jenkins, sus posiciones respectivas, y compartidas, estarían más cerca de la del autor estudiado en el libro que estamos reseñando. Y esto significa que hay una admiración empática por Ginzburg a lo largo de todo el libro. Es decir, a un positivismo académico ingenuo, Serna y Pons contraponen su propio realismo informado, con ciertos toques constructivistas y narrativistas pero alejados de lo que los autores denominan escepticismos y relativismos postmodernos. Ya desde los comienzos de la década de los noventa, se han venido interesando por la historia cultural, por la historia desde abajo y por la propia reflexión historiográfica, metodológica y teórica. Por una parte, uno de los primeros libros conjuntos fue, nada menos, que una monografía histórica sobre la ciudad de Valencia en el siglo XIX, titulada La ciudad extensa: la burguesía comercial-financiera en la Valencia de mediados del XIX (Valencia: Centre d'Estudis d'Història Local, 1992). Y, por la otra, en 1993, ambos autores publicaron "El ojo de la aguja: ¿De qué hablamos cuando hablamos de microhistoria?”, un artículo pionero que fue publicado en el número 12 del instrumento editorial de la Asociación Española de Historia Contemporánea, la revista Ayer, en un ejemplar dedicado a la reflexión historiográfica reciente. Si Justo Serna se ha interesado más por la función pública del intelectual, colaborando en medios periodísticos y digitales, con columnas y reflexiones de opinión política, algunos de los cuales pueden 
ser leídos en Bestiario español. Semblanzas contemporáneas (Madrid: Huerga y Fierro, 2014), El pasado no existe. Ensayo sobre la Historia (Madrid: Punto de Vista Editores, 2016) y Todo es falso salvo alguna cosa (Madrid: Punto de Vista, 2016), Anaclet Pons ha renovado la meditación profesional con una obra reciente sobre la historia en una cultura digital como la nuestra. El libro se titula El desorden digital: guía para historiadores y humanistas (Madrid, Siglo XXI, 2013). Del interés conjunto y compartido por la lengua de la historia, por el lenguaje histórico y sus distintos rostros, dan fe los estudios individuales sobre Antonio Muñoz Molina, Umberto Eco o Natalie Zemon Davis, así como sus estudios de historia cultural. Pero volvamos al libro que justifica estas líneas.

El título del libro, microHistoria. Las narraciones de Carlo Ginzburg, ya nos pone sobre la pista de tres cuestiones importantes. La primera de ellas es el hecho de que la "h" de la palabra "microHistoria" esté en mayúscula. Los autores parecen querer decir, de esta manera, que, frente a otras posiciones historiográficas, la historia sigue siendo algo importante, algo que destacar, algo "mayúsculo". La segunda de ellas es el término "narraciones", que vincula este estudio con otro de los intereses historiográficos tanto del profesor Serna como del profesor Pons: la importancia de la narración en la disciplina histórica. El hecho de que para contar la historia haya que contar una o varias historias. El pasado está hecho de acciones, que se representan con historias. La necesidad que tiene el historiador de poner toda la información que ha extraído paciente y cautelosamente de las fuentes de una forma ordenada y cronológica: narrativamente, en suma. Esta segunda cuestión también enlaza -un tanto paradójicamente, si se quiere- la obra de Ginzburg con la obra de Hayden White. Curiosamente, quien escribe las líneas de esta reseña, nunca ha entendido muy bien el porqué del debate y la disidencia intelectual, ciertamente encarnizada, en algunos momentos y aspectos, entre el historiador estadounidense, recientemente fallecido, y el autor de Ojazos de madera e Historia nocturna. Revisando las actas del Congreso que Saul Friedlander publicó en Harvard University Press en 1991 sobre los límites de la representación histórica, Probing the limits of Representation, uno no entiende muy bien la pertinencia de los cargos que Ginzburg lanzó contra White. De hecho, curiosamente, el propio White siempre se sintió un poco alejado de las acusaciones que historiadores como el propio Ginzburg, o Momigliano, por poner otro señero ejemplo, vertieron sobre él. Por otro lado, una de las cosas sorprendentes del libro de Serna y Pons es el hecho de que parece que bascula entre las ventajas de una posición historiográfica como la de Ginzburg, alejada de un positivismo ingenuo, que es el tipo de positivismo rankeano ciertamente reinante en buena parte de la disciplina, especialmente fuera de los muros de la academia, aunque también dentro de ella, y una posición narrativista como la del propio White. Aunque en este punto, tanto los autores como el autor estudiado preferirán adscribirse, supongo, a la obra de narrativistas insignes como Marrou, Walsh o Arthur C. Danto. Es decir, nos quedamos con el narrativismo y un poquito del constructivismo de base, pero nos alejamos intelectualmente del escepticismo figurativo y tropológico de un White, un Ankersmit o un Jenkins. En las páginas treinta y siete y siguientes del libro, el lector interesado en esta cuestión podrá encontrar pruebas de lo que comento. Finalmente, la tercera cuestión importante a la luz del título del libro que estamos reseñando se refiere al propio nombre que figura en él: Carlo Ginzburg. De hecho, desde el mismo frontispicio editorial, el lector ya sabe que estamos ante una monografía sobre el historiador italiano. 
El libro que comentamos es un "ensayo transversal", es una monografía que propone una "descripción densa" del autor estudiado, una visión caleidoscópica del rompecabezas ginzburgiano, aunque, en el fondo, supone una síntesis, además de una actualización, respecto de varios textos anteriores de sus dos autores. Precisamente, el libro que comentamos nace al rebufo del éxito de La historia cultural. Autores, obras, lugares (Madrid: Akal, 2005; segunda edición de 2013). Si bien, sin embargo, es un descendiente directo, aunque adelgazado de Cómo se escribe la microhistoria. Ensayo sobre Carlo Ginzburg (Valencia: Frónesis, 2000). En este sentido, en buena medida, microHistoria es un ejemplo de esa clase de historia de las mentalidades tan querida por buena parte de la escuela de los Annales, aunque reduciendo la escala así como las aspiraciones estructurales.

Estamos ante una monografía que aúna peripecias biográficas, análisis textuales e historia intelectual, sin menoscabo de una acertada contextualización tanto histórica como historiográfica, tanto del autor como de sus obras, tanto de los intereses intelectuales de Ginzburg como de su recepción allende los mares, los tiempos y las culturas. En este sentido, la estructura del libro que comentamos permite al lector ir adentrándose en las distintas capas espacio-temporales, incluso temáticas, por las que se mueve el texto.

En microHistoria, Serna y Pons dedican los capítulos segundo y tercero, "El punto de partida" y "La disposición de la trama", a estudiar el origen y la vida editorial de $E l$ queso y los gusanos, así como a analizar detalladamente el contenido y las características formales de un libro de tal entidad e influencia historiográfica. De hecho, nuestros autores dedican nada menos que sesenta páginas a esta obra, fundamental en el desarrollo profesional de Carlo Ginzburg. Y lo hacen con claridad, sencillez, que no simplicidad, y profundidad. Este primer tercio del libro, de casi ciento setenta páginas, se muestra como un esfuerzo encomiable de análisis historiográfico pero, también, de síntesis, donde la obra de Ginzburg ocupa un papel especial, a la vez que la disección sobre la etiqueta "microhistoria".

Pero ¿qué es la "microhistoria"? Cualquier lector que se sienta interesado por este libro, y se acerque a él con tiempo y curiosidad, hará bien en leer la autobiografía intelectual que los autores han decidido introducir justo al final del texto junto con dos entrevistas de diversas épocas y lugares, realizadas a Ginzburg. Leyendo estas breves pero jugosas páginas, cualquier lector estará sobre aviso respecto de las principales peripecias biográficas del autor estudiado así como de su evolución e intereses intelectuales. Contado con sus propias palabras, igual que han hecho insignes pensadores como Paul Ricoeur o George Steiner, Ginzburg nos cuenta los detalles más importantes de su particular partida de ajedrez historiográfica, por utilizar una metáfora de su propia preferencia. En "Cómo se escribe la microhistoria", capítulo sexto del libro que estamos reseñando, Serna y Pons se dedican a analizar algo que el propio Ginzburg nunca ha explicado en detalle: qué se esconde detrás de su perspectiva historiográfica microhistórica y cuáles son sus ascendentes y puntos de contacto intelectual, en particular con la obra de Levi (p. 115). Pero es, sin embargo, al comienzo del libro, donde los autores ofrecen su tesis sobre el origen de la microhistoria: "el impulso, el éxito [de esta corriente historiográfica], derivaba de una profunda crisis de las ideologías, de una crisis de la razón y de los metarrelatos, manifiesta ya a finales de los años sesenta" (p. 6). El libro que comentamos intenta contextualizar esta profunda crisis, para situar la pasión moral y el 
prurito intelectual con los que Ginzburg escribió su obra más conocida. Y los autores no evitan las críticas mordientes, aquí y allá, a lo largo del libro que estamos reseñando, como la de la página ciento tres.

Por su parte, en el capítulo quinto de microHistoria, Serna y Pons se ocupan de estudiar algunas de las principales polémicas que Ginzbug ha mantenido, a lo largo de los años, con otras posiciones historiográficas y con otros autores, especialmente con la corriente postmoderna. Así, el capítulo titulado "Contra el escepticismo" está dedicado a censurar una "actitud escéptica, postmoderna, que había que combatir" (p. 76). ¿Por qué? Pues porque había que subrayar la importancia de la "consciencia narrativa", es decir, de la utilidad de la narración para la representación historiográfica pero, también, había que rechazar las consecuencias más extremas de esta consciencia. Y, en concreto, las consecuencias a las que habían llegado autores como el propio White. Por ello, Ginzburg se puso como meta rechazar toda forma de relativismo epistemológico, algo que tiene que ver con las fuentes, no con la relación semántico-indiciaria entre el discurso histórico, las fuentes y el pasado que se intenta reconstruir e incluso de toda forma de escepticismo postmoderno (p. 7). Por otro lado, en la página setenta y seis, los autores señalan que Ginzburg se ha referido "explícita y escuetamente" a la obra de Hayden White pero, a continuación, dedican varias páginas a estudiar las referencias de Ginzburg al historiador estadounidense, lo que parece desmentir ese "escuetamente". Y, por cierto, ¿dónde está ese White que se señala en la misma página? Parece que solo hay un anti-White...

Por otro parte, en la página ochenta y uno, se señala que a White no le interesa la relación del texto histórico con la realidad que dice reconstruir, cuando esto es no exactamente así, ni siquiera en Metahistory (pp. 81 y 89). A White, como a todo historiador, le interesa que el resultado de una investigación histórica sea lo más fiel y verosímil posible respecto de la información proporcionada críticamente por las fuentes disponibles. Lo que creo que White defiende es que la perspectiva global que unifica una representación historiográfica determinada -lo que incluye, pero es algo más que, cada una de las afirmaciones o negaciones que contiene un "libro de historia"-, no puede compararse con una realidad pasada para averiguar cuánto de verdad incluye. Entre otras razones porque el pasado ya no existe, no se puede observar. Pero también por un conjunto de razones retórico-literarias y lingüístico-discursivas que Serna y Pons podrían haber explicado en este libro. Otra de las cuestiones interesantes que se pueden matizar es el análisis que Ginzburg realiza de los autores que han influido en White. Aquí, Serna y Pons señalan algunas de sus incoherencias e inexactitudes, como lo que se señala sobre Gentile (p. 87), o lo que afirman en las páginas noventa y cinco y ciento tres, pero, falta a la postre, un estudio de los autores que más han influido en el pensamiento y en la obra de White, de Bossenbrook a Pepper, pasando por Auerbach, Nietzsche o Marx. Además, creo que hierra Ginzburg al relacionar a White con el pensamiento conservador (p. 94). Nada más lejos de la realidad: White siempre se ha reconocido como un intelectual de izquierdas, marxista y con un claro compromiso ético con la emancipación y con la libertad humanas. Como el que podría representar un autor al que White siempre ha mencionado: el propio J.M. Coetzee. De hecho, una de las cuestiones más interesantes del libro que estamos comentando es que abre la puerta a lo que Dominick La Capra lleva defendiendo toda la vida: la importancia de la empatía del historiador, o la falta de ella, incluso su inevitabilidad, que puede y, -ipor qué no decirlo?-, debe ponerse del lado de las víctimas de la historia, como hizo Carlo Gizburg en El Queso y los gusanos. 
Para ir terminando con nuestro análisis, y como no solo de virtudes y haberes vive el intelectual, acaso conviene señalar, también, algunos de los debes del texto que reseñamos. No termina de sorprender del todo el hecho de que el texto padezca de varios descuidos y erratas, aquí y allá. Descuidos en la redacción (sinónimos forzados; palabros como, por ejemplo, la historia como "exhumación"; y, repeticiones, "sea como fuere", etc.) y erratas en la edición (pp. 45, 85, 91, 101, 105, 107, 133 y 161). No por casualidad, la historia editorial occidental ya comenzó con las prisas, urgencias y erratas de la primera edición de El Quijote, compitiendo con otras novelas de caballería. Además, en esta época de ritmos vitales y académicos frenéticos, con la intromisión ontológica y neuronal de lo digital, parece que la escritura y la revisión a cuatro manos no termina de asegurar la limpieza de un borrador libre de estos "errores en el mundo" que son las erratas. En todo caso, la labor editorial podría haber evitado estas pequeñas molestias al lector con una revisión más cuidada y detallada. Y que conste que, para quien escribe estas líneas, estos deslices textuales no son, ni de lejos, lo más importante de una obra de esta naturaleza y virtudes. Sin embargo, sí que es de justicia señalar alguna que otra cuestión controvertida del libro, meras disonancias epistemológicas, que sería un placer debatir y aclarar con los propios autores. Por usar una metáfora que aparece mencionada varias veces en el libro que comentamos, la del ajedrez, aparte de la del "rompecabezas", y que permite señalar el desarrollo de la carrera intelectual del propio Ginzburg, dichas disonancias serían, más bien, como algún tipo de imprecisión táctica o posicional cometida por un jugador de ajedrez con el tiempo en contra. Me estoy refiriendo, por ejemplo, a la página doce, cuando Serna y Pons afirman que la microhistoria concibe el pasado como una materia reconstruida a partir de fragmentos, como una averiguación, como una pesquisa que "pone en relación conjetural vestigios, huellas, indicios". Si realmente es una relación conjetural, ¿por qué atacar con tanto ahínco la postura de autores como Hayden White? Igual comienza siendo una relación conjetural, con humildad y tesón, pero termina siendo una reconstrucción fidedigna, basada en la capacidad del historiador por superar la imperfección de las fuentes... ya con ímpetu profesional. Aunque sí, aunque luego el propio Ginzburg se encarga de matizar diciendo que hay "conjeturas verdaderas" y "conjeturas falsas" (p. 91). Sin embargo, en varias partes de las declaraciones de Ginzburg, parece encontrarse una posición cercana a la de White, como cuando se afirma que "opera aquí una suerte de restricción formal: cada forma literaria nos fuerza a descubrir una cosa y a ignorar otra" (p. 95). O como cuando se alega que "la idea de una narrativa histórica simple es tan absurda como la idea de la prueba histórica irrefutable" (p. 97).

Por otro lado, los autores subrayan un aspecto interesante del trabajo historiográfico de Ginzburg: "su voluntad explícita de hacer visibles los procedimientos, los itinerarios y los obstáculos de la interpretación" (p. 14), algo que les relaciona, a los tres, con la obra de los principales autores postmodernos. Incluso se señala, en el libro, la naturaleza elaborada, construida, del saber histórico, siempre sometido a una paciente y constante tarea de revisión (p. 17). Y ello pese a que en una ocasión, los autores del libro afirman que Ginzburg quiere mostrar esos obstáculos, esas dificultades de la investigación, "al menos retóricamente" (p. 71). El historiador no se encuentra el pasado en los archivos, no puede representarlo haciendo una copia de papel carbón del conjunto de fuentes disponibles. Al contrario, las fuentes nos señalan el pasado pero no lo representan. La representación es un producto del historiador. Y con las mismas fuentes, 
dos historiadores diferentes harán dos monografías también diferentes. Incluso contrapuestas. Y obviar esta realidad es no darse cuenta de lo que está detrás del trabajo del historiador. Finalmente, Ginzburg, como Serna, como Pons y como el propio White, han intentado vincular y cohesionar "la investigación empírica" con "la reflexión teórica" (p. 9), es decir, han intentado elaborar una auténtica filosofía de la historia, personal, circunstancial pero también anclada en buena medida a los movimientos de una época histórica, con sus diferencias y malentendidos enriquecedores, como los que muestran, con todo lujo de detalles, el libro, interesantísimo y ricamente condensado, que estamos terminando de reseñar.

En 1981, en una entrevista publicada por el diario El País, Ginzburg afirmaba que "no hacía historia para mis colegas, sino para la otra gente". Esta posición history from below -no exactamente académica, profundamente ética- aproxima a Ginzburg, profesionalmente, a un pensador como Arnaldo Momigliano, pero también, paradójicamente, a un historiador como Hayden White. Ginzburg, en esa entrevista de 1981, afirmó lo siguiente: "yo no estoy interesado en escribir para mis colegas, sino para la otra gente". Y sigue diciendo:

pero esto no impide que yo sea un verdadero historiador en sentido de absolutamente riguroso, si prefieres, muy filológico, muy científico. Después de la investigación, naturalmente, vendrá el problema del discurso. Hay historiadores que escriben bien y los hay que escriben mal, y escribir bien entre los historiadores suele ser sinónimo de muy retórico... Yo no he metido notas a pie de página, sino al final del texto, para facilitar una lectura a los no especialistas, pero ahí está el trabajo con todo rigor. Y he hecho una narración, pero no he inventado nada.

Este penúltimo libro de Serna y Pons nos ayudan a entender en qué medida ese "problema del discurso" no se circunscribe únicamente al hecho de si un historiador escribe bien o escribe mal, o al hecho de si usa o no una narración para ordenar los resultados de su investigación historiográfica.

Espero, sinceramente, que estas líneas animen al lector a adentrarse en esta emocionante y sintética obra de conjunto sobre la microhistoria y la carrera de Carlo Ginzburg, con la intención de reflexionar, sin prejuicios y con profundidad, sobre la complejísima tarea del historiador.

Aitor Bolaños de Miguel

UNIR (Universidad Internacional de La Rioja)

ambdem5@gmail.com 
Fecha de recepción: 28 de mayo de 2019

Fecha de aceptación: 3 de junio de 2019

Publicación: 30 de junio de 2019

Para citar este artículo:

Aitor Bolaños, "Justo Serna y Anaclet Pons, microHistoria. Las narraciones de Carlo Ginzburg. Granada: Comares, 2019, 184 pp.”, Historiografías, 17 (enero-junio, 2019): pp. 159-165. 